\title{
ESCLAVOS MUSULMANES EN LOS HOSPITALES DE CAUTIVOS DE LA ORDEN MILITAR DE SANTIAGO (SIGLOS XII Y XIII)
}

\begin{abstract}
Las órdenes militares dispusieron desde su fundación de mano de obra esclava en sus tierras, pero la institución que mejor sirve para estudiar la esclavitud en los siglos XII y XIII en los reinos de León y Castilla son los hospitales para la redención de cautivos de la Orden de Santiago. Estas instituciones disponían de espacio para alojar a los cautivos mientras se negociaban rescates con los poderes islámicos, y atendían a la redistribución de aquellos musulmanes que, por no haber sido redimidos, pasaban a ser esclavos de la propia orden o a ser vendidos en los mercados de los reinos cristianos. Los escasos documentos de la sección de Órdenes Militares del Archivo Histórico Nacional dedicados a esclavos ayudan a comprender el funcionamiento del tráfico, trabajo y liberación de este colectivo.
\end{abstract}

Palabras clave: esclavitud; hospitales; órdenes militares; mudéjares.

\author{
Ana EcheVARría Arsuaga \\ UNED, Madrid ${ }^{1}$
}

Military Orders had slave manpower in their lands since their foundation. However, the hospitals for ransoming captives owned by the Order of Santiago are the best example of how slavery worked in the kingdom of Leon-Castile during the twelfth and thirteenth centuries. These houses had enough room to provide lodging for captives while ransoms were being negotiated. They also helped to redistribute those Muslims who, lacking this possibility, became slaves of the order itself, or were sold in the slave markets of the kingdom. The scarce records kept in the Archivo Histórico Nacional, section Órdenes Militares, referring to slaves, help to understand the development of traffic, work and manumission of these people.

Key words: Slavery; Hospitals; Military Orders; Mudéjars.

En 1237, Abdalia ('Abd Allāh) de Sahagún compraba a un moro llamado Hameth a Gonzalo Márquez, freire de la orden de Uclés. La transacción tenía lugar en pleno reino de León, en el Hospital de Tiendas de Villamarín, que poseía la Orden de Santiago en las cercanías de Carrión, en el Camino de Santiago. La venta de un esclavo musulmán probablemente doméstico, a un mudéjar vecino de una villa tan importante y septentrional del reino como Sahagún, en el marco de uno de los hospitales que una orden militar como la de Santiago po-

${ }^{1}$ Este artículo se ha realizado dentro del Proyecto de Investigación HUM200608644/FILO, titulado «Movilidad geográfica y social de la población musulmana de la Península Ibérica (siglos XI-XIII)». 
seía para la atención de peregrinos, en un lugar tan alejado de la frontera como el Camino de Santiago, es una rareza en la documentación castellanoleonesa, si bien conocemos ejemplos similares en los reinos de Aragón y Portugal. En Aragón y Valencia los mudéjares compraban a otros musulmanes, en muchos casos con el fin de liberarlos, y se conservan repetidas prohibiciones durante los siglos XIV y XV de que los musulmanes poseyesen o comprasen esclavos cristianos o recientemente convertidos. La trata de esclavos a través de los puertos de la corona aragonesa y mediante los intermediarios, sobre todo genoveses, complementaba la fuente de esclavos por antonomasia: las guerras peninsulares contra el Islam. Sin embargo, la corona de León y Castilla cuenta con muchos menos datos sobre la situación de los esclavos, fueran éstos musulmanes o no, en su territorio ${ }^{2}$.

El primer problema que se presenta a la hora de abordar este tema es cómo «descubrir» a los esclavos en el entramado de una sociedad feudal como la castellanoleonesa. La ambigüedad del vocabulario referido a la esclavitud en las fuentes cristianas plenomedievales deriva de la utilización de palabras heredadas de la tradición latina del imperio romano, que se utilizaban tanto para designar la esclavitud propiamente dicha como para nombrar a la servidumbre de tipo doméstico, agrícola o artesanal con diferentes grados de libertad: servus, ancilla y mancipia fueron los términos más utilizados, junto con las denominaciones de raza o religión - sarracenus, maurus, sclavus - y, a veces, la descripción de características físicas de la persona ${ }^{3}$. Evidentemente, en la Península Ibérica se recurrió abundantemente a estas últimas palabras, pues la mayoría de los esclavos lo eran de guerra, por lo que esta nomenclatura servía además para justificar el estatuto legal del esclavo en cuestión. Por otro lado, podía mencionarse alguna circunstancia más, como el hecho de ser cautivo, neófito o converso. En cuanto a la definición de estas personas, la servidumbre - léa-

2 Aparte de los escasos datos incluidos en la monografía de C. Verlinden (L'esclavage dans l'Europe médiévale, Gante, 1977, I, 128, 149-156), en parte por la parquedad de fuentes documentales publicadas en la fecha en la que el autor realizó su trabajo, tenemos un artículo más reciente de Soyer, F., "Muslim Freedmen in León, Castile and Portugal (1100-1300)", Al-Masāq, 18,2 (2006), 129-143, que trata este tema desde el punto de vista de la manumisión, sobre todo.

3 Heers, J., Esclavos y sirvientes en las sociedades mediterráneas durante la Edad Media, Valencia, 1989, 16-19; Verlinden, L'esclavage, II, 111, 969-970.

Al-Qanțara (AQ) XXVIII 2, julio-diciembre 2007, pp. 465-488 ISSN 0211-3589 
se esclavitud-, es considerada antinatural, y fruto de una "postura o entendimiento» ${ }^{4}$.

El esclavo doméstico de la domus romana se mantiene, pues, durante toda la Edad Media bajo el nombre de siervo o cautivo doméstico ligado a la familia o al colectivo social para el que presta sus servicios (siervos de la Iglesia, de las órdenes militares, etc.). También hay lo que se denomina siervo «de la tierra», destinado al trabajo predominantemente agrícola, así como a explotaciones de otros recursos naturales. Cualquiera de los señores disfrutaba de todas las capacidades legales respecto al esclavo - venderlo, cederlo, cambiarlo o enajenarlo-, salvo que estuviera estipulado de otra manera, debido a los diversos tipos de servidumbre o esclavitud que podían darse en el Medievo ${ }^{5}$.

Aparte de la esclavitud por cautiverio, la más habitual y en la que el cautivo perdía todos sus derechos a no ser que pudiera estipular un rescate, se daban otros casos recogidos en la legislación castellana ${ }^{6}$. En primer lugar, los nacidos de siervas, pues eran las madres las que transmitían dicho estatus. Además, estaban aquellas personas que, siendo libres, se dejaban vender, siempre que se cumplieran cinco condiciones: que hubiera consentimiento, que obtuviera parte del precio, que él sepa que es libre, que el que lo compre piense que es siervo, y que la persona hubiese cumplido la mayoría de edad, fijada en veinte años ${ }^{7}$. Los ejemplos más frecuentes de esta situación eran la esclavitud temporal por deudas, voluntaria y válida hasta que se saldara el importe debido, o la venta voluntaria de un hombre libre para evitar el hambre, la po-

${ }^{4}$ Alfonso X, Las Siete Partidas, Salamanca, 1555, facs. 1974, III, f. 54v. Partida IV, Tít. XXI, Ley I. El comienzo del título XXI, "Sobre lo siervos", dice: «Servidumbre es postura e establecimiento que fizieron antiguamente las gentes, por la qual los omes que eran naturalmente libres se fazien siervos e se meten a señorío de otro, contra razón de natura».

${ }^{5}$ Sobre los derechos que poseían los esclavos musulmanes a practicar y ser juzgados por la ley islámica, a firmar un contrato, a efectuar transacciones comerciales o a apelar ante los tribunales, véase Catlos, B., "Esclavo o ciudadano: fronteras de clase en la Corona de Aragón (siglo XIII)", en De l'esclavitud a la llibertat. Esclaus i lliberts a l'Edat Mitjana, Barcelona, 2000, 151-165, especialmente 154-155.

6 Alfonso X, Las Siete Partidas, I, f. 110 y ss. Partida II, Tít. XXIX: "De los captivos y de sus cosas que derecho han", se dedica expresamente a la situación de los cautivos del reino que están en poder del enemigo, y a todos los derechos que les deben ser respetados, sin entrar en ningún caso en la situación a la inversa.

7 Alfonso X, Las Siete Partidas, III, f. 54v. Partida IV, Tít. XXI, Ley I. Una casuística similar se conserva en los Assises de la Cour des Bourgeois del reino de Jerusalén, Verlinden, L'esclavage, 966-967. 
breza o males de otro tipo, para servir durante dos años, cinco, o de por vida, pudiendo ser revendido si se mantenían las condiciones de la venta inicial ${ }^{8}$. Estos casos de lo que podríamos denominar una «esclavitud moderada» o «mixta» implicaban el trato correcto del esclavo por parte del amo, por las características especiales de su situación. Por su parte, el pontificado romano condenaba a la esclavitud a los cristianos que hubiesen proporcionado armas a los musulmanes, los amigos o aliados de los sarracenos, dentro del marco de prohibiciones de comercio de cosas vedadas en tiempos de guerra (es decir, armas, víveres, esclavos, maderas y metales preciosos) ${ }^{9}$.

Evidentemente, la facilidad de obtención de cautivos de guerra en el contexto de las luchas entre musulmanes y cristianos en la Península Ibérica es el primer factor que propició el mantenimiento de la esclavitud durante todo el período andalusí y, posteriormente, bajo los soberanos cristianos peninsulares. Las campañas de Alfonso VII entre 1130 y 1145 proporcionaron gran número de esclavos, a juzgar por las noticias de la Chronica Adefonsi Imperatoris ${ }^{10}$. Y no sólo los reyes, también las grandes ciudades y villas con suficiente caballería organizaban expediciones. La necesidad de mano de obra era acuciante, fuera para la colonización de los amplios espacios conquistados para el cultivo o para labores pesadas como la minería, la construcción a gran escala y el mantenimiento de estructuras viarias y de regadío. Además, gran parte del servicio doméstico era esclavo, y estaba formado por cautivos musulmanes.

La Iglesia aprovechó desde muy pronto este sistema para aprovisionarse de campesinos que cultivaran los inmensos dominios territoriales que se le fueron concediendo conforme la frontera avanzaba hacia el sur y que ella misma se preocupó de aumentar mediante compras y donaciones de particulares. Igualmente, tenían necesidad de artesanos, que a veces eran libres, pero otras se encontraban sometidos a la servi-

8 Así lo declara la Partida V, Tít. V, Ley XLV y el Fuero Real, Libro III, Tít. X, Ley VIII, Fuero Real, Valladolid, 1979, 89. Cf. Soyer, "Muslim Freedmen in León”, 132.

${ }^{9}$ La legislación pontificia se recoge también en las Partidas, f. 55, Partida IV, Tít. XXI, Ley. Cf. Heers, Esclavos y sirvientes, 19, 45. Sobre la diversidad de condiciones y derechos del esclavo en el Islam, similares a estos planteamientos, véase Puente, $C$. de la, "Entre la esclavitud y la libertad: consecuencias legales de la manumisión según el derecho mālikí", Al-Qanțara, XXI (2000), 339-360, esp. 340-353.

${ }^{10}$ Chronica Adefonsi Imperatoris, L. Sánchez Belda (ed.), Madrid, 1927, 23, 32-34, 42, 90-95, 104-105, 147. Cf. Verlinden, L'esclavage, I, 150-151.

Al-Qanțara (AQ) XXVIII 2, julio-diciembre 2007, pp. 465-488 ISSN 0211-3589 
dumbre, tanto en el ámbito rural como en la ciudad. La dedicación del clero a sus funciones litúrgicas favorecía, evidentemente, su utilización de otras manos para el trabajo, y se justificaba este hecho aludiendo a su condición de paganos, musulmanes, herejes o cismáticos ${ }^{11}$.

Lo mismo que el resto de la Iglesia, las órdenes militares utilizaron esclavos en sus dominios desde su aparición en el reino de Jerusalén ${ }^{12}$. La participación de las órdenes militares en la captura y posterior movilización de esclavos musulmanes en el reino castellanoleonés ha sido insuficientemente estudiada, debido en parte a los escasos documentos que se refieren a estas actividades. Sin embargo, la labor asistencial de la orden de Santiago a través de los hospitales de cautivos que se fundaron durante los siglos XII y XIII tiene como contrapartida una importante dimensión de gestión de los destinos de los cautivos musulmanes que caían en sus manos. Debido a las condiciones de la guerra y a las concesiones que los monarcas fueron haciendo a la orden, las capturas y repartos de prisioneros como botín de guerra permitirían a los caballeros desarrollar una serie de actividades que, sin duda, les fueron rentables económicamente. En primer lugar, se les permitió conservar todos aquellos prisioneros de alto rango que cayeran en sus manos durante el combate, pudiendo cobrar sus rescates hasta una cantidad de mil maravedíes. Por otra parte, se les autorizó a negociar los rescates de cautivos cristianos, principalmente mediante el intercambio por otros prisioneros musulmanes, para lo que aprovechaban sus actividades y contactos en la frontera. A los caballeros se les obligaba a invertir en rescate de cautivos el botín que obtuvieran personalmente en una campaña contra los musulmanes ${ }^{13}$, e incluso ingresos extraordinarios como

11 Heers, Esclavos y sirvientes, 91-93, 105-107. Sobre las posiciones de la Iglesia desde época paleocristiana hasta el siglo IX, véase Verlinden, L'esclavage, I, 20-25; sobre donaciones de esclavos y emancipación, 80-96, 98-105. Para el caso hispano, véase también Ruiz de la Peña, J. I., "Siervos moros en la Asturias medieval", Asturiensia medievalia, 3 (1979), 139-161; Buresi, P., La frontière entre chrétienté et Islam dans la Péninsule Ibérique. Du Tage à la Sierra Morena (fin XIe-milieu XIIIe siècle), París, 2004, 110-118.

${ }^{12}$ La Crónica del templario de Tiro explicaba que cuando Baybars propuso un intercambio de cautivos a los francos de Acre en 1263, los templarios y hospitalarios se negaron a hacerlo aduciendo que sus esclavos musulmanes eran todos artesanos y les causaría grandes pérdidas económicas prescindir de ellos. Kedar, B., "The subjected Muslims of the Levant", en Muslims under Latin Rule, 1100-1300, J. M. Powell (ed.), Princeton, 1990, 135-174, 153.

13 «Capítulo 26. Que los fríeles den para catiuos lo que ganaren en tierra de moros. Mandamos, por estrecho mandamiento, que todo aquello que los fríeles, con ayuda de 
las concesiones de bula de cruzada, podían dedicarse al rescate de cautivos o al mantenimiento de las fortalezas fronterizas ${ }^{14}$. Como base de estas operaciones, se establecieron los hospitales de cautivos, con el fin de acoger a los cristianos que volvieran a Castilla después de su estancia en al-Andalus, pero sin duda también para acoger temporalmente a los cautivos musulmanes mientras se preparaba su intercambio. Por último, aquellos cautivos de los que nadie respondiera y que no pudieran ser intercambiados, sin duda quedaron al servicio de la orden y fueron trasladados a otras casas, donde ejercerían los oficios que se les asignasen, fuera de tipo doméstico o profesional, proporcionando a la orden una mano de obra barata.

Los hospitales de cautivos santiaguistas se han estudiado siempre desde el punto de vista de las actividades asistenciales de la orden, comparables a las de las órdenes de Tierra Santa, mucho más imbuidas de ese espíritu de cuidado y protección de los peregrinos. Concretamente, el capítulo tercero de la regla original ordena recibir y dar las cosas necesarias a los pobres de Jesucristo, considerándose los más pobres de entre ellos a los cautivos de guerra ${ }^{15}$. Esta faceta era tan importante como la militar de lucha contra el infiel —o incluso contra otros cristianos, si era necesario-, o la religiosa de extender la fe cristiana ${ }^{16}$. Dentro de esas actividades asistenciales, la fundación de hospita-

Dios ganaren de los moros por sus personas, lo den con gran charidad para sacar catiuos de poder de los moros», Regla y establecimientos de la caballería de Santiago del Espada, León, 1998, 178.

${ }^{14}$ Aguado de Córdova, A. F., Alemán y Rosales, A. A. y López Agurleta, J., Bullarium Equestris Ordinis S. Iacobi de Spatha, Madrid, 1719 (en adelante BS), 249-251, cit. Ayala Martínez, C. de, Las órdenes militares hispánicas en la Edad Media (siglos XII-XV), Madrid, 2003, 609.

15 "Que quando el defensor libra alguno de la captiuidad de los paganos, o defendiendo haze que no lo lleuen en captiuidad, da de comer al hambriento y de beber al sediento, y uiste al desnudo, y uisita al doliente, y al que está en la cárcel. ¿Quién puede más auer hambre, o más sed, o entonces estar más desnudo, o más enfermo, puesto en más dura cárcel que el que está captiuo, detenido en poder de los moros?», Regla, 170, 173-179.

16 Ayala, Las órdenes militares, 606-610; Martín Rodríguez, J. L., Orígenes de la Orden Militar de Santiago (1170-1195), Barcelona, 1974, 29, 31; Forey, A., "The Military Orders and the Ransoming of Captives from Islam (twelfth to early fourteenth centuries)", Studia monastica, 33 (1991), 259-279, reed. Military Orders and Crusades, Variorum, 1994; Brodman, J. W., Ransoming Captives in crusader Spain: the Order of Merced on the Christian-Islamic Frontier, Filadelfia, 1986, 10-11; Josserand, Ph., Église et pouvoir dans la Péninsule Ibérique. Les ordres militaires dans le royaume de Castille (1252-1369), Madrid, 2004, 148-155.

Al-Qanțara (AQ) XXVIII 2, julio-diciembre 2007, pp. 465-488 ISSN 0211-3589 
les para la redención de cautivos se consideraba parte del primer fin, la lucha contra el infiel, y se compaginaba con actividades de otro tipo, como la atención a los peregrinos en los hospitales del Camino de Santiago, o los verdaderos hospitales «de sangre» y lazaretos ${ }^{17}$.

La necesidad de canalizar el intercambio de cautivos en la frontera, así como de garantizar la atención y cuidado a aquellos hombres recién llegados de territorio enemigo, su reinserción en la sociedad cristiana y su transporte a sus lugares de origen, a menudo lejanos de la propia frontera, fue una preocupación presente entre los gobernantes cristianos, aunque no por eso dejaron de practicarse las actividades redentoras sin cobertura institucional propia ${ }^{18}$. De hecho, el primer hospital de cautivos perteneció a lo que Ayala ha denominado una «milicia concejil sacralizada». Fue fundado en Ávila, por la hermandad de los fratres de Ávila, bajo la advocación de San Mateo ${ }^{19}$. $\mathrm{Su}$ aparición en la frontera occidental entre Castilla, León y, al sur, las tierras ora cristianas, ora musulmanas, en torno a Talavera, no es fortuito. La estructura social de Ávila, fuertemente dominada por las milicias de caballeros serranos, favorecía las continuas incursiones en territorio enemigo, lo mismo que la existencia de señores de la guerra musulmanes en la zona de Talavera. La ruta que atravesaba el Sistema Central les permitía llegar hasta el mismo centro de poder almohade, en Sevilla. Los repartos de esclavos como botín eran algo común, y todos los grupos sociales de la ciudad se beneficiaban de ellos, siendo más importantes los concedidos a la Iglesia para la construcción de la catedral, que se llevaba a cabo en ese momento, y los destinados a la construcción de la muralla ${ }^{20}$. Incluso se habla de un mercado de es-

17 Madrid y Medina, A., "Los comienzos de la hospitalidad santiaguista: el Hospital de Ávila", Espacio, Tiempo y Forma, Serie III, Historia Medieval, 17 (2004), 371-379, espec. 373-376, sin embargo no distingue entre la redención de cautivos y los hospitales de sangre o de misericordia.

18 Sobre redenciones de cautivos por parte de la orden de Avis, de Calatrava y Alcántara, y acuerdo entre órdenes para la liberación de sus caballeros, véase Lomax, D. W., La Orden de Santiago (1170-1275), Madrid, 1965, 164-165; Ayala, Las órdenes militares, 610.

${ }^{19}$ A ellos donó Alfonso VIII la villa de Bolobres en una fecha que, según J. L. Martín y J. González, podría datarse según los confirmantes entre 1168-1170. Martín, Orígenes, 209; Madrid, "Los comienzos de la hospitalidad", 372; Ayala, Las órdenes militares, 135.

${ }^{20}$ La donación de esclavos a la catedral y a las autoridades, en Ariz, L., Historia de las grandezas de la ciudad de Ávila, Alcalá de Henares, 1607, 2. ${ }^{a}$ parte, fols. 5r-49v. Las numerosas incursiones aparecen detalladas también en la Crónica de la población de Ávila, A. 
clavos en la propia ciudad. No es de extrañar, pues, la aparición de esta hermandad en la ciudad y la fundación de un hospital de cautivos, a través del cual se canalizarán los intercambios de prisioneros con los musulmanes. En la documentación, éste aparece vinculado al monasterio de San Mateo y a una capellanía, extramuros de la ciudad. La incorporación de los fratres de Ávila y todas sus posesiones a la orden de Santiago en 1172 trajo consigo el paso de titularidad del hospital, que pasaría a incorporarse así, casi casualmente, a las propiedades de la orden, y que sin duda tuvo sus consecuencias a la hora de planificar la evolución de la hospitalidad santiaguista ${ }^{21}$.

La iniciativa política a la hora de institucionalizar esta práctica partió de Alfonso VIII — que en esta política se separa claramente de su vecino leonés-, y su fundación se sitúa a lo largo de la retaguardia fronteriza de la época: durante su reinado se fundan y dotan los hospitales de Toledo, Cuenca y Huete, Alarcón y Moya, que vienen a unirse al ya mencionado de Ávila. Coherente con su política de favor hacia la orden de Santiago, de la que a su vez se beneficiaba, el rey encomendó los hospitales para el rescate de cautivos a esta orden, que ya contaba con el primero ${ }^{22}$.

$\mathrm{Su}$ distribución y localización aparece claramente condicionada por la necesidad de redistribuir y dispersar a los cautivos una vez sacados del teatro de operaciones bélicas. El reparto de cautivos afectaba sobre todo a mujeres y niños de las plazas conquistadas, e incluso esclavos que mantenían su estatus bajo los cristianos. Incluso se die-

Hernández Segura (ed.), Valencia, 1966. En cuanto a mención de esclavos, es bien conocido el testamento del prior de la catedral de Ávila, Martín, quien donaba en 1197 a sus dos moras manumitidas, Zeme y Fátima, dos lechos con todo su ajuar y seis modios de harina de trigo, Barrios, A. (ed.), Documentos de la Catedral de Ávila (siglos XII-XIII), Ávila, 2004, 86-87, cf. Tapia Sánchez, S., La comunidad morisca de Ávila, Salamanca, 1991, 48.

${ }^{21}$ En mayo de 1172 los freires de Ávila se unen a la orden de Santiago: Martín, Orígenes, 226-227, doc. 53. A partir del siglo XIII, con la compra de varias propiedades agrarias por parte de Sancho Asensio, comendador del hospital, comienza la serie de documentos sobre la ampliación de terrenos de la casa, pero deja de hacerse referencia a su carácter redentor progresivamente, quizá por su lejanía de la frontera a partir de la conquista de Sevilla. Archivo Histórico Nacional (en adelante AHN), Órdenes Militares (en adelante OM), Uclés, carp. 56, 3. A mediados del siglo XIII la fundación era mixta: el hospital estaba a cargo de un comendador, y el convento regido por una comendadora, situación que se mantendría durante los siglos siguientes, Madrid, "Los comienzos de la hospitalidad", 377-379.

${ }_{22}$ González, J., El reino de Castilla en la época de Alfonso VIII, Madrid, 1960, I, 618-623; Martín, Orígenes, 95.

Al-Qantara (AQ) XXVIII 2, julio-diciembre 2007, pp. 465-488 ISSN 0211-3589 


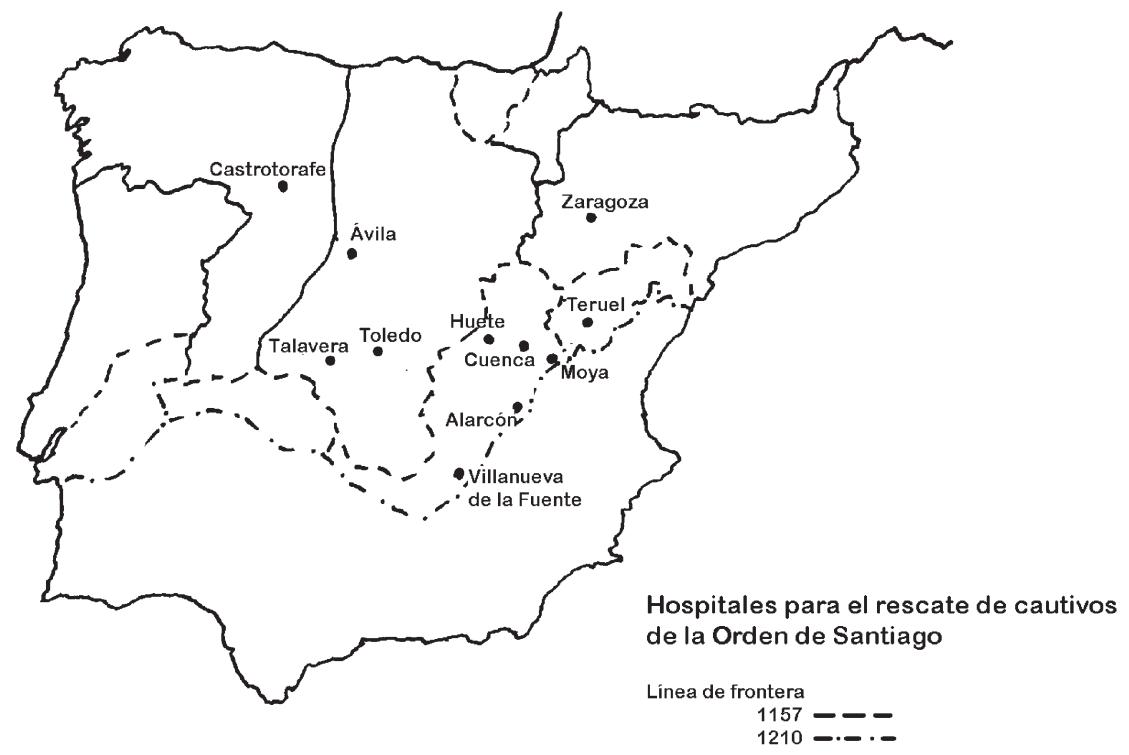

ron casos en que los mozárabes fueron esclavizados junto con los musulmanes y tuvieron que protestar por ello ${ }^{23}$. Al ser divididos entre los hospitales de la orden, podían repartirse los gastos de vigilancia y manutención de los prisioneros hasta el momento de su intercambio; se dividían los cautivos entre diferentes poblaciones, con la posibilidad de utilizarlos para rescatar a cristianos de su misma localidad, y se podía aprovechar también la mano de obra esclava en caso de que el período de estancia del cautivo se prolongara ${ }^{24}$.

En 1180 funcionaban ya los de Toledo y Cuenca. Aquel año Alfonso VIII concedía al primero la mitad del portazgo de la puerta toledana de la Bisagra ad extrahendos christianos captiuos in terra maurorum, y teniendo en cuenta que el importe de la renta se estimaba en 300 áureos, los santiaguistas debían comprometerse a redimir

23 Verlinden, L'esclavage, 134-136.

${ }^{24}$ Heers, Esclavos y sirvientes, 50-51. Los templarios aragoneses también concentraban a los esclavos adquiridos mediante sus actividades militares en las encomiendas provinciales, como Monzón, Gardeny y Miravet, antes de distribuirlos por sus propiedades agrarias, sobre todo durante el siglo XIII, según Sans i Travé, J. M. a "Els templers catalans, propietaris d'esclaus", en De l'esclavitud a la llibertat. Esclaus i lliberts a l'Edat Mitjana, Barcelona, 2000, 309-324, 317.

Al-Qanțara (AQ) XXVIII 2, julio-diciembre 2007, pp. 465-488 ISSN 0211-3589 
por lo menos 30 cautivos al año, ya que se fijaba en 30 áureos el precio del rescate ${ }^{25}$. Por su parte, el hospital de Cuenca, situado en la «llanura entre el camino y el Júcar», probablemente con dificultades de despegue, recibía de manos particulares una sustanciosa dotación en 1182, que sin duda contribuyó a revitalizarlo. Era un buen momento para pensar en este tipo de fundaciones y el obispado concedió una bula a todos los que hicieran limosnas al hospital. El propio concejo de Cuenca concedió pronto como fuero para la redención de cautivos a través del hospital, y para su mantenimiento, una serie de rentas en especie: los que trabajaban la tierra con una yunta de bueyes debían proveerles de un almud de trigo al año, y medio los que trabajaban con un solo animal; los propietarios de ganado bovino debían pagar cuatro denarios anuales; los cazadores de venado, cuatro pieles, y los pastores que tuviesen cien ovejas o más, una pieza al año ${ }^{26}$.

Para completar el sistema de hospitales, al sur del Sistema Central se fundaron dos nuevas casas, aún en el siglo XII: en Talavera (1194) y Huete (hacia 1198), relacionadas sin duda con el transporte de cautivos y esclavos hacia Ávila y Cuenca, y desde allí hacia el resto del reino ${ }^{27}$. Pocos años después, seguramente como resultado de la derrota de Alarcos y de los previsibles enfrentamientos con los almohades, se fundaban también por iniciativa real los hospitales de Alarcón (antes de 1203) y Moya (1211), ambos estrechamente relacionados con el de Cuenca, en cuyos dominios terminaron por integrarse ${ }^{28}$.

Organizativamente, y ya desde estos primeros momentos, el hospital constituía el centro de un señorío de la orden que, como el resto de

25 Bula de fundación del Hospital de Toledo, en BS, 21-22; González, Alfonso VIII, II, doc. 338; Martín, Orígenes, 76-77; 95, doc. 138; 347-348, doc. 165; 403, doc. 225. Cf. Ayala, Las órdenes militares, 606. 1219, junio, 16. Segovia: Fernando III da al hospital de cautivos que la orden tiene en Toledo, fundado por su abuelo Alfonso, la heredad de Yegros. González, Fernando III, II, pp. 96-97. Sobre otros precios de cautivos, véase Buresi, La frontière, 113.

26 Para la donación de Cuenca, $B S, 26-27$; la concesión de indulgencia de cuarenta días a cambio de limosnas por parte del obispado en 1184, 30; las donaciones del concejo en 1184, en 29. Todo ello se estudia desde el punto de vista patrimonial en Iradiel, P., "Bases económicas del hospital de Santiago en Cuenca: tendencias del desarrollo económico y estructura de la propiedad agraria", AEM, 11 (1981), 181-246, 184-185.

27 Donación de las casas para construir el hospital de Talavera, en 1194: BS, 44; el inventario de sus bienes en 1238, en AHN, OM, carp. 323, 8. La lista de sus propiedades, entre ellas una cadena con veinte collarines para los prisioneros y tres pares de esposas en Buresi, La frontière, 117.

${ }^{28}$ Fundación del hospital de Alarcón y donaciones de Alfonso VIII en 1203, González, Alfonso VIII, II, doc. 543 y BS, 49-50; Iradiel, "Bases económicas", 184-186.

Al-Qantara (AQ) XXVIII 2, julio-diciembre 2007, pp. 465-488 ISSN 0211-3589 
las encomiendas, se sustentaba sobre el producto obtenido de sus tierras, ganados y derechos jurisdiccionales. Además de eso, contaba con la especial protección de la Iglesia, a través de los pontífices y obispos, como Urbano III y Gregorio VIII, quienes potenciaron las limosnas a favor de las instituciones hospitalarias a través de sus bulas de indulgencias. También los concejos en cuyos territorios se asentaban contribuían al mantenimiento de los hospitales, que redundaba al fin y al cabo en el bien de los posibles cautivos de sus milicias en la guerra contra los musulmanes. De esta manera, las dotaciones para los hospitales de cautivos podían ser de varios tipos: tierras y heredades para su manutención, donaciones a la orden por parte de antiguos cautivos, fondos en dinero para emplear en el rescate de cautivos y cautivos conseguidos en combate, para su intercambio o venta ${ }^{29}$. Finalmente, lo mismo que otras instituciones, podían recibir directamente esclavos mediante mandas testamentarias, como la que hizo Egidio de Leforín a la casa de la Merced de Teruel, a la que dispuso que fuesen entregados dos moros que tenían los templarios encomendados y que, si éstos muriesen o huyeran en el plazo de un año después de su muerte, los templarios debían dar por ellos a la casa de la Merced cien jucefinos ${ }^{30}$.

Sobre esta base económica, los hospitales santiaguistas establecieron una sólida organización de rescate de cautivos cristianos, que les podía reportar importantes beneficios. Pensemos que los freires no sólo canjeaban prisioneros, sino que, además, podían negociar el rescate de cautivos musulmanes a cambio de importantes sumas en metálico. La mitad del importe de tales sumas, cuando los musulmanes valieran más de mil áureos, fue transferida por el rey a la orden de Santiago desde 1190, lo que permitiría a la orden reinvertir estas sumas en la redención de otros cautivos ${ }^{31}$.

A partir de 1200 los grandes señores locales se incorporaron a la financiación de los hospitales de cautivos, quizá animados por las bulas

29 Por ejemplo, la donación hecha por Tello Pérez y Pedro Gutiérrez a favor de la Orden de Santiago para su hospital de cautivos, de unas heredades en Cuenca en 1182. Cf. González, Alfonso VIII, III, 826; ibidem, II, pp. 568-570, doc. 338; Martín, Orígenes, 98.

301220 , enero, 1. «Item mando ad domum Mercedis Turolio II sarracenos quos tenent de me comendatos et si moriuntur vel fugiunt post meum transitum usque ad unum annum, ut tradant illos C juzefinos per eos fratres Templi de rebus meis». Mur i Raurell, A., La encomienda de San Marcos. La Orden de Santiago en Teruel (1200-1556), Teruel, 1988, 48, 317-318, doc. 17.

${ }^{31}$ Martín, Orígenes, 436-437, doc. 263.

Al-Qanțara (AQ) XXVIII 2, julio-diciembre 2007, pp. 465-488 ISSN 0211-3589 
pontificias, y posiblemente también presionados por las necesidades bélicas de rescate de miembros de sus familias, y por las concesiones de los concejos. Esta financiación podía hacerse por dos vías: a hospitales ya fundados por iniciativa real, como la efectuada por Alfonso Téllez al Hospital de Talavera en 1226, que en varias obras pasa por ser la verdadera fundación del hospital, o la fundación privada, como la de la casa de la Merced de redención de cautivos de la orden en Teruel, más tarde conocida como encomienda de San Marcos, establecida por Don Lope de Varea y su esposa, Sancha Pérez de Azagra ${ }^{32}$.

La expansión de los hospitales de cautivos santiaguistas por Aragón puede seguirse en el hospital de Zaragoza (1228), el de Teruel (antes de 1200) y el de Segorbe, estas dos últimas poblaciones también en la retaguardia de la frontera. Sin embargo, la iniciativa no cuajaría en el reino de León, cada vez más alejado de la frontera, donde la fundación de las casas de Castrotorafe (Extremadura, h. 1220) apenas paliaron el fracaso del otro hospital de redención, el de Sancti Spiritus de Salamanca, dotado en 1223 por Alfonso IX, que no llegó a prosperar, quedando convertido en monasterio femenino. La posterior unión del reino con el de Castilla hizo innecesaria la continuación de la política hospitalaria en sus tierras ${ }^{33}$.

Los hospitales, regidos por un freire comendador, actuaban como centros de concentración de los cautivos musulmanes procedentes de la frontera — de ahí su necesaria cercanía a ésta, aunque en el momento de la ofensiva almohade se prefirió trasladarlos un poco más al nortehasta el momento de su canje, de acogida de los cautivos cristianos recién llegados, y de redistribución de éstos y de aquellos musulmanes que, al no ser canjeados o liberados, debían permanecer en territorio cristiano como esclavos. Los pocos datos que conocemos de la gestión de las rentas de estos hospitales provienen de otra institución, el segundo hospital de redención de Teruel, bajo la advocación de San Redentor (1188-1198), creado por el rey aragonés Alfonso II y entregado a la orden de Montegaudio. Según los acuerdos constituyentes de 1188, al menos la cuarta parte de las rentas del conjunto de la institución serían

32 Mur, La encomienda, 39-41, 47; Forey, "The Military Orders", 269.

33 En 1176, Fernando II de León había donado la villa a la orden, $B S$, 18-19; Martín, Orígenes, 259-260, doc. 79. Tras enajenar la villa durante la guerra contra Alfonso VIII, Alfonso IX de León la devuelve a la orden y funda el hospital, González, Fernando III, I, 261, 504-505. 
destinadas a la redención de cautivos; de su recaudación se encargaría un freire que fielmente aplicaría la disposición sobre las rentas del grano - una vez retenida la simiente y salarios y comida de jornaleros (mercenariorum), bueyes y jumentos-, sobre los beneficios del vino que se vendiera, y sobre las crías de los animales, el botín de guerra (lucris exercituum) y los donativos de bienes muebles ${ }^{34}$.

Jurídicamente, según figura en la documentación de la orden de Calatrava, los esclavos musulmanes formaban parte del patrimonio de cada casa perteneciente a una orden militar, cuya explotación aseguraban, y por ello no podían ser vendidos individualmente, puesto que eran bienes constituyentes de la propiedad. Este estatuto puede ser la causa de que no se conserven menciones específicas a estos esclavos en la mayor parte de los documentos de compraventa del reino de Castilla, puesto que quedaban incluidos en «todas las pertenencias» que se citaban globalmente a la hora de transferir una propiedad. En los estatutos de Calatrava de 1304, se ordena que los comendadores llevasen al capítulo un inventario de sus casas y propiedades, entre las cuales debían contarse sus esclavos. Por ejemplo, el inventario de Fuente del Emperador (1267), incluye a seis moros y una mora ${ }^{35}$.

Aunque no contamos con documentación directa de cómo se hacían los transvases de personas de un lugar a otro, hay indicios que permiten entrever que el comendador o su delegado sería el encargado de viajar con los cautivos musulmanes al lugar designado para el intercambio, donde debía asegurarse de efectuarlo y regresar con el número de cristianos correspondiente a su mismo hospital de procedencia. Tanto los fueros fronterizos, desde Extremadura y Ávila hasta Cuenca, como los portazgos de los que tenemos noticia escrita, recogen los impuestos que generaba el tránsito de musulmanes cautivos, esclavos y libres al pasar por esas poblaciones ${ }^{36}$. La propia orden santiaguista, en su portazgo de Alarilla, cobraba un cuarto de morabetino por un moro que fuera de un lugar a otro, y un morabetino de

${ }^{34}$ Sainz de la Maza, R., La Orden de Santiago en la Corona de Aragón. La encomienda de Montalbán (1210-1327), Zaragoza, 1980, I, doc. 13. Mur, La encomienda, 41-46, 50-51; Forey, A., The Templars in the Crown of Aragón, Oxford, 1973, 274; cf. Ayala, Las órdenes militares, 609.

35 Josserand, Église et pouvoir, 358.

36 Verlinden, L'esclavage, I, 102, 119, 162, 221, 245, 323-324, 572-581. Para un análisis de los fueros relativos a la parte occidental de Castilla, Echevarría, A., "La 'mayoría' mudéjar en León y Castilla: legislación real y distribución de la población (siglos XI-XIII)", 
cada «moro de redención» ${ }^{37}$. También Alarcón disponía de un importante puesto de portazgo para todas las mercancías procedentes del reino de Valencia.

De la misma manera, en los artículos de los fueros de Cuenca, Alcaraz y Alarcón, es decir, en lugares donde había hospitales de redención, se protegía el derecho de un propietario a heredar la propiedad de un moro converso que muriera sin hijos. Es muy posible que éste fuese el caso de algunos de los esclavos musulmanes que la orden tenía en dichos hospitales, cuya paternidad era sin duda difícil de demostrar. Hasta qué punto era común que estos hombres se convirtieran, incluso mediante una promesa de libertad, es algo que ignoramos ${ }^{38}$.

Otra forma de conseguir fondos para aplicar a la redención mediante rescate era el intercambio del cautivo cristiano por productos comerciales. Esta práctica viciada, pero probablemente corriente, estaba penalizada por la Iglesia, que prohibía todo tipo de comercio con los musulmanes en tiempos de guerra, bajo pena de excomunión. Puede que ésta fuera una de las razones por las que en la regla de los templarios se contiene una prescripción que autoriza a los freires a frecuentar la compañía de caballeros excomulgados ${ }^{39}$. La contradicción entre teoría y práctica era tan evidente que las consultas a Roma se sucedían, tanto por parte de las órdenes mendicantes, también obligadas al trato permanente con musulmanes, como por parte de las órdenes militares. Por ejemplo, Gregorio IX tuvo que resolver las dudas que le plantearon los provinciales de las órdenes de Predicadores y franciscanos en 1234, sobre la excomunión por la prohibición de comerciar en el reino de Túnez, refiriéndose sobre todo a los genoveses,

En la España Medieval, 26 (2006), 7-30. Los más interesantes a este respecto son los de Zorita, Plasencia y Béjar.

37 «Del moro de renitión, I mor. (...) E de moro que passare de un logar ad altero, quarta de mor». El portazgo de Alarilla es de 1172-82. Martín, Orígenes, 233-234, doc. 58. En la compilación de las leyes capitulares aprobadas bajo el maestrazgo de don Alonso de Cárdenas (1477-1493) se establece un arancel en el portazgo de doce maravedíes por cada esclavo o esclava. Compilación de las Leyes Capitulares de la Orden de la Cavallería de Santiago del Espada, introducción P. A. Porras Arboledas, Valladolid, 1992, 214.

38 O'Callaghan, J., "The Mudejars of Castile and Portugal in the Twelfth and Thirteenth Centuries", en Muslims under Latin Rule (1100-1300), J. M. Powell (ed.), Princeton, 1990, 11-56; para el fuero de Cuenca, arts. 9 y 12, 254; Fuero de Alarcón, art. 167, 177; Fuero de Alcaraz, art. 3.72, 177.

39 Según Ayala, «para atraerlos al redil eclesiástico a través de la purificadora experiencia de la milicia sagrada», pero quizá también haya que tener en cuenta motivos económicos. Ayala, Las órdenes militares, 16.

Al-Qanțara (AQ) XXVIII 2, julio-diciembre 2007, pp. 465-488 ISSN 0211-3589 
aunque tambien se menciona a hispanos ${ }^{40}$. Pocos años después, en 1239, el mismo Gregorio IX absolvía a los freires santiaguistas que, con el fin de rescatar cautivos, habían vendido animales u otros productos a los musulmanes («pro redemptione captivorum aut alio modo dando sarracenis animalia et res alias seu vendendo»), incurriendo por ello en excomunión ${ }^{41}$. Acto seguido, ordenaba al obispo de Palencia que levantasen la pena que pesaba sobre ellos y autorizaba, a partir de entonces, que los hospitales santiaguistas de redención pudieran traficar con los musulmanes utilizando bueyes y otros animales - nunca caballos y mulas, puesto que eran animales aptos para la guerra y, por ello, mercancías vetadas - a cambio de cautivos ${ }^{42}$.

A pesar de las medidas de fuerza empleadas, como el uso de cadenas y prisiones, los caballeros tuvieron tantos problemas con las fugas de cautivos como los propietarios laicos y eclesiásticos particulares ${ }^{43}$. El traslado de los cautivos no garantizaba su sujeción, como demuestra la huida de la prisión de la casa de la Merced de Moya de seis esclavos trasladados allí desde el hospital fronterizo de Alarcón. Una vez que el comendador don Gonzalo Díaz salió en su busca, le fueron

40 Diplomatario de San Raimundo de Peñafort, J. Rius Serra (ed.), Barcelona, 1954, doc. XVII.

${ }_{41}$ AHN, OM, Santiago, carp. 2, II, 5; BS, 111; Martín, Orígenes, 420, doc. 244.

42 «Gregorius episcopus servus servorum Dei. Venerabili frater episcopo et dilecto filio decano Palentinis, salutem et apostolicam benedictionem. Cum ce- [...] volucres et terre bestias rerum conditor humane creature subdiderit, quam sue nobilitate nature mortalibus pretulit universis dignum est ut que iugum subiectionis a sui origine pertulerunt humanis usibus deputate sibi precipue in eius oportunitatibus subtrahantur. Oblata siquidem nobis dilectorum filiorum magistri et fratrum militie Sancti Jacobi petitio continebat quod cum quedam hospitalia sui ordinis redemptioni captivorum sint specialiter deputati ipsos non possunt a sarracenis redimere nisi rependant boves vel alia animalia pro eisdem. Quare ne Christi famuli detineantur compede perpetue servitutis vel ictu sevi ensis occumbant cum pium sit et misericordie grandis opus existat taliter eos de vinculo captivitatis educi ut animalium recompensatione brutorum que pro eis gratis et pietatis volunt intuitu exhibere ipsis liberationis remedium impendant et restituatur perdite privilegium libertatis, nobis humiliter supplicarunt ut predicto modo redimendi captivos a sarracenus sibi licentiam largiremur. Eorum igitur supplicationibus inclinati discretioni vestre per apostolica scripta mandamus quatinus, si est ita, eis auctoritate nostra concedatis licentiam postulatam. Proviso attentius quod equi et muli cum quibus christianos impugnare valeant occasione tali nullatenus tribuantur et ne in fraudem per commutationem huiusmodi aliquid attemptetur. Data Laterani XIII kalendas martii pontificatus nostri anno duodecimo». AHN, OM, Santiago, carp. 2, II, 6; BS, 112.

${ }^{43} \mathrm{La}$ familia del esclavo podía depositar fianza para que las cadenas le fuesen retiradas. González Palencia, A., Los mozárabes de Toledo en los siglos XII y XIII, Madrid, 1926-1930, III, 230, doc. 939. 
arrebatados por los caballeros y peones de la vecina villa de Requena. Puesto que el concejo de Moya tenía pactos con el de Requena y no podía romperlos por ese motivo, firmó una concordia por la que daba fianzas al comendador por valor de 1200 maravedíes ${ }^{44}$. Las fugas de esclavos se consideraban un fenómeno principalmente masculino, favorecido por la proximidad de comunidades musulmanas que pudieran acogerles o de puertos de salida hacia destinos de territorios islámicos. La mayor integración de las mujeres en la vida familiar, un mayor grado de reclusión y la dedicación a faenas menos duras pudieron favorecer este estado de cosas ${ }^{45}$.

La manumisión de los esclavos tuvo un importante papel en la formación de muchas aljamas castellanas ${ }^{46}$. Técnicamente, podía distinguirse al musulmán liberado (aforrado), del rescatado, y a éste a su vez del moro libre ordinario ${ }^{47}$. Los datos aportados por la documentación de la orden de Santiago permiten conocer algunos aspectos más sobre el proceso de manumisión, conocido también a través de fuentes legales y de la documentación toledana. El Fuero Romanceado de Uclés, casa principal de la Orden, preveía la liberación de los esclavos moros mediante la entrega de un tercio del precio que habían pagado por ellos más el canje de un vecino de la villa que estuviera cautivo en tierras del Islam, disposición muy similar a la del fuero de Cuenca, modelo indudable de los fueros de frontera de la zona ${ }^{48}$. Otra

${ }^{44}$ Los hechos ocurrieron en 1234. AHN, OM, carp. 100-2, 18; Iradiel, "Bases económicas", 184-185, n. ${ }^{\circ} 13$, y ed. doc. 19, cit. Ayala, Las órdenes militares, 607-608. Ver apéndice.

${ }^{45}$ Salicrú i Lluch, R., "Entre el reclam de les terres islàmiques i l'escapada septentrional: l'instituzionalització de la por a les fugues d'esclaus a la Catalunya tardomedieval", en De l'esclavitud a la llibertat. Esclaus i lliberts a l'Edat Mitjana, Barcelona, 2000, 87-134, 94-99.

${ }^{46}$ Sobre sus variedades, véase Heers, Esclavos y sirvientes, 234-248; Soyer, "Muslim Freedmen in León", 135-142, Partida IV, Tít. XXII, Partidas, II, fols. 56v-59r. Un modelo de carta de manumisión en la Partida III, Tít. XVIII, Ley XC, Partidas, II fol.

47 Burns, R.I., "La manumisión de un musulmán: un documento doble de Valencia en el 1300", Sharq al-Andalus, 5 (1988), 141-145, 141. El esclavo mencionado es, en realidad, la esclava conversa Francesca.

48 «Tít. 169. Toto homne qui moro ovieret comparado et ipso moro voluerit cativo christiano sacar vicino de Ucles, det tercia parte de ganancia a suo domino de quanto lo comparo. Et si hoc fecerit et non exierit illo christiano, tornent suo moro a suo domino». Rivera Garretas, M., La encomienda, el priorato y la villa de Uclés en la Edad Media (1174-1310), Madrid-Barcelona, 1985, 72. El de Cuenca dice: «De eo qui maurum comparaverit [si captivum xristianum pro eo dare voluerit, quid emptor habeat accipere]. Quicumque maurum comparaverit in Concha, pro quo captivum xristianum dare velint, accipiat

Al-Qanțara (AQ) XXVIII 2, julio-diciembre 2007, pp. 465-488 ISSN 0211-3589 
cuestión era la manumisión del musulmán sin mediar el intercambio con otro cautivo cristiano, extremo que era aún más complicado en el caso de las mujeres. Desconocemos el precio que la esclava musulmana llamada Ayxa, casada con un tal Alihuelo, pagaría al comendador de Criptana D. Sancho Aznárez, a cambio de su manumisión. Su carta, lo mismo que las de otros musulmanes, especificaba que se le autorizaba a moverse libremente tanto en tierras cristianas como islámicas ${ }^{49}$. Sin embargo, la permanencia de su marido en tierras de la orden hace suponer que dicha autorización era simplemente nominal. Eso significa que la mujer pasaría a formar parte automáticamente de la población mudéjar de los lugares de la orden. La cláusula final de su carta es aún más llamativa: si tenía algún hijo de su marido, Alihuelo, la mitad de su propiedad correspondería a la orden ${ }^{50}$. Evidentemente, Alihuelo era también esclavo, y es en virtud de ese estatus por lo que su hijo continuaría perteneciendo en parte a la orden. Sin embargo, según las Partidas era la mujer la que transmitía la condición de esclavitud ${ }^{51}$ :

Nascido seyendo ome de padre libre e de madre sierva, estos atales son siervos porque siguen la condicion de la madre quanto a servidumbre o franqueça; pero si acaesciese que atal seyendo preñada, la franqueassen, el fijo que della nasciesse seria libre, si quier no lo truxesse en su vientre la madre, despues que fuesse franqueada, mas de una ora, e aun quando quier menos. E maguer despues tornasse la madre en servidumbre, siempre fincaría el fijo libre, por aquel tiempo que lo traxo la madre despues que la franquearon, quier fuesse poco o mucho. Mas los fijos que nasciessen de madre libre e de padre siervo serian libres, porque siempre siguen la condicion de la madre, segund que es sobredicho.

Era de esperar que, con el tiempo, el marido consiguiera pagar su rescate trabajando, de forma que no hubiera limitaciones para su progenie, pero ésta es una manifestación más de lo lejos que estaba la vida de la legislación.

dominus mauri previum quod constitit, et decem aureos de lucro, et dat eum postquam maurus testificatus fuerit, si venditus aut male missus fuerit, dominus mauri extrahat xristianum de captivitate, recipiendo precium supradictum». Cap. I, XXV (versión sistemática), Fuero de Cuenca (formas primitiva y sistemática, texto latino, texto castellano y adaptación del fuero de Iznatoraf), R. de Ureña Smenjaud (ed.), Madrid, 1935.

49 Burns, "La manumisión de un musulmán", 142, 144.

50 1253. AHN, OM, carp. 81,5. El documento ha desaparecido, pero está descrito detenidamente en el catálogo.

${ }_{51}$ Partida IV, Tít. XXI, Ley II. Partidas, II, fol. 54v. Lo mismo ocurría en el derecho islámico, Puente, C. de la , "Mujeres cautivas en 'la tierra del Islam"”, Al-Andalus-Magreb, 14 (2007), 19-37. 
Dada la naturaleza mixta de la orden de Santiago no sería extraño que las casas destinadas a albergar esclavas musulmanas estuviesen dirigidas por comendadoras, pero no ha quedado más rastro de esta dedicación que la referencia ya mencionada a la división del hospital de San Mateo de Ávila. Antes de 1243 existía incluso una casa en Villanueva de la Fuente, cerca de Alcaraz, donde vivían las cautivas musulmanas de los freires ${ }^{52}$.

No nos hemos referido en este trabajo a los otros hospitales, de peregrinos, con los que contaba la orden en el Camino de Santiago: San Marcos (León), San Miguel del Camino, la alberguería en el monte Sispiazo y el lazareto y hospital de pobres de Las Tiendas, en Villamarín. A pesar de que en ellos no había espacio más que para esclavitud doméstica cuyas referencias se han perdido, es en este espacio donde encontramos la única referencia a la venta de esclavos por parte de la orden. A ella nos hemos referido al comienzo, para destacar la interacción entre mudéjares libres y musulmanes esclavos en las posesiones santiaguistas del norte de la Meseta. En la venta del esclavo Hameth a su correligionario Abdalia de Sahagún, destaca el bajo precio que se paga por él, cincuenta maravedíes alfonsíes, que darían una indemnización de cien maravedís en caso de daño y perjuicio, que contrastan con los doscientos en los que se valoró a los esclavos de Moya. Asimismo, es interesante comprobar que a su dueño musulmán se le autoriza a realizar todas las operaciones que haría un cristiano con un esclavo: venta, empeño o manumisión. En el documento aparece también don Franco como «fiador de sanamiento, de furto e de jubina», tal como impone la legislación («cuemo el rey manda») ${ }^{53}$.

52 Sólo poseemos de esta casa la mención que hace Fernando III en el contexto de la donación a la orden de la iglesia de Villanueva, aldea de Alcaraz, el 11 de septiembre de 1243, y los términos son muy vagos: «Dono itaque vobis et concedo illam ecclesiam de Villanova quam ego mihi acceperam quando dedi Villanovam concilio de Alcaraz, et dono eam vobis ut eam semper iure hereditario habeatis et in eternum possideatis pacifice et quiete, cum omni decima ipsius ville, et cum omnibus pertinentibus ab eandem, sicut eam prius pleno iure tenebatis antequam darem ego Villamnovam concilio de Alcaraz. Et mando firmiter et defendo quod nec archiepiscopus nec episcopus aliquis alius construat vel edificet aliam ecclesiam preter istam in hac prefacta villa, et ad istam semper veniat totum concilium Villenove. Dono insuper vobis et concedo illos domos ubi sarracene vestre morari solebant». González, J., Reinado y diplomas de Fernando III, Córdoba, 1986, II, 274-275, doc. 716. AHN, OM, carp. 365, 1-2. Documentos de 1239 y 1243. Probablemente el segundo es una sentencia dada por Fernando III en forma de privilegio rodado.

${ }_{53}$ AHN, OM, carp. 325, 23. Ver apéndice documental. Sobre la necesidad de fiador en la compraventa de esclavos, González Palencia, Los mozárabes, I, 243.

Al-Qanțara (AQ) XXVIII 2, julio-diciembre 2007, pp. 465-488 ISSN 0211-3589 
En 1245, lo mismo que ocurriría más adelante en 1263-1264, el maestre de la orden, Pelay Pérez Correa, se enfrentaría a serias disidencias internas, bajo las acusaciones de autoritarismo y de utilizar abusivamente los recursos de la orden. Lo cierto es que tenía graves problemas económicos, aparte de querer fortalecer la posición institucional del maestre (separando claramente los bienes de la mesa maestral, concediendo fueros, etc.), lo que le obligaba a tratar de asegurarse los fondos provenientes de sus vasallos moros ${ }^{54}$. El contacto continuo con los musulmanes hacía a los freires susceptibles de incurrir en excomunión permanentemente, por lo que el Maestre pidió a Inocencio IV un permiso especial para tratar con los mudéjares que habitaban en sus tierras, bien para cobrarles los impuestos que debían pagar anualmente, bien para realizar los intercambios comerciales necesarios para la orden y para los propios musulmanes, a lo que el Papa accedió en dos bulas. Si en la primera de ellas facultaba al maestre para que cobrase tributos, negociase préstamos, vendiese y comprase todo lo que necesitase a los musulmanes ${ }^{55}$, en la segunda autorizaba a todos los miembros y familiares de la orden que hubiesen incurrido en penas por estas prácticas para que pudiesen pedir la absolución en sus diócesis de residencia ${ }^{56}$. Lo más interesante de estos documentos

54 Ayala, Las órdenes militares, 208.

55 «Inocentius episcopus servus servorum Dei. Dilectis filiis magistro et fratribus ordinis militie Sancti Iacobi. Salutem et apostolicam benedictionem. Sincere devotionis affectus quem ad personam nostram et Romanam geritis Ecclesiam nos inducit ut vestris petitionibus benignum accomodemus auditum, eas precipue ad exauditionis gratiam admittendo, que salutem anime necnon et vestrum comodum specialiter respicere dinoscuntur. Significastis siquidem nobis quod vos plura castra, villas et alia loca de sarracenorum eripuistis manibus et vestre ditione divina operante potentia subiecistis, in quibus nonnulli habitant sarraceni, qui certa tributa annis singulis vobis reddunt. Quare nobis humiliter supplicastis, ut cum eisdem sarracenis contrahendi mutuum, eis vendendi, ac ab ipsis emendi res vobis necessarias concederemus vobis liberam facultatem. Nos igitur vestris supplicationibus inclinati, auctoritate presentium vobis concedimus postulata. Nulli ergo omnino hominum liceat hanc paginam nostre concessionis infringere, vel ei ausu temerario contraire. Si quis autem hoc attemptare presumpserit, indignationem omnipotentis Dei, et beatorum Petri et Pauli apostolorum eius se noverit incursurum. Data Lugdunum nonas septembris pontificatus nostri anno octavo». AHN, OM, carp. 2, II, 13.

56 «Inocentius episcopus servus servorum Dei. Dilecto filio magistro ordinis militie Sancti Iacobi. Salutem et apostolicam benedictionem. Ex parte tua nobis extitit intimatum quod nonnulli ordinis tui fratres et ipsorum familiares, sarracenis victualia et animalia vendiderunt, et receperunt mutuum ab eisdem. Quare nobis humiliter supplicasti ut saluti eorum in hac parte providere paterna sollicitudine curaremus. Nos igitur animarum salutem super omnia cupientes, tuis supplicationibus inclinati, presentium auctoritate concedimus ut diocesani locorum in quibus predicti fratres et familiares existunt, possint 
es el reconocimiento de la situación de facto que se vivía en las tierras de la Orden, lo mismo que ocurría en Tierra Santa.

La época de pujanza de la hospitalidad de órdenes militares en general, y de la santiaguista en particular, finaliza durante el siglo XIII. El alejamiento de la frontera, la propia ralentización del proceso reconquistador y la evolución en el tratamiento a los prisioneros de guerra, además de la aparición de la figura del mudéjar, que reducía sensiblemente el número de cautivos que llegaban a las instituciones santiaguistas, imposibilitaba el intercambio de cautivos y privaba a los hospitales de una parte importante de su razón de ser y de sus rentas. Pelay Pérez Correa, consciente de ello, solicitó y obtuvo de Inocencio IV permiso para seguir disfrutando de las rentas y bienes hospitalarios, aunque su destino no fuera la redención de cautivos. Concretamente lo consiguieron en el caso del hospital de Toledo en 1250 , pero no es difícil imaginar que el privilegio papal intentaría ser aplicado a otras instituciones análogas; el problema era que aunque las rentas fueran aplicadas in altos pios usus, como expresa el documento papal, ni los concejos ni muchos fieles particulares se sentirían a partir de entonces incentivados para proseguir en su actitud colaboradora, máxime teniendo en cuenta que la solicitud de dispensa pontificia fue acompañada por nuevos privilegios papales que autorizaban a los santiaguistas a mantener relaciones comerciales con los sarracenos, al margen ya de la antigua justificación redentora. Ayala relaciona esta bula con el reconocimiento de la inviabilidad del mantenimiento de los hospitales, y a partir de su concesión no dejan de apreciarse las resistencias de particulares y autoridades civiles a seguir pagando las rentas que previamente habían ofrecido para el rescate de cautivos ${ }^{57}$.

ipsis hac vice iuxta formam ecclesie absolutionis beneficium impertiri, iniuncto eis quod de iure viderunt iniungendum. Data Lugdunum octava idus Septembris pontificatus nostri anno octavo». AHN, OM, Santiago, carp. 2, II,18. BS, 180-181.

57 «Inocentius episcopus servus servorum Dei. Dilectis filiis magistro et fratribus ordinis militie Sancti Iacobi. Salutem et apostolicam benedictionem. Illis precibus libenter benignum prestamus auditum que honestati congruunt et consonant equitati, et eis potius exauditionis ianuam aperimus que dinoscuntur pro conservandis religiosorum viribus specialiter interponi. Significastis siquidem nobis quod inclite recordationis A. rex Castelle quoddam hospitale ad honorem Santi Jacobi apud Toletum fundavit bonis propriis et dotavit ac illud cum omnibus viribus ac pertinentiis suis vobis pia liberalitate concessit, statuens ut eius redditus et proventus necessariis fratrum ibidem existentium de ipsis dumtaxat deductis expensis in redemptionem cederent christianorum a sarracenis illarum 
Como hemos visto, desde fechas muy tempranas los concejos que albergaban hospitales en sus términos establecían subsidios colectivos a favor de ellos con el fin de apoyar su acción redentorista y su mantenimiento. Iradiel ha sugerido que estas iniciativas podían más bien intentar limitar el acceso a la propiedad urbana y territorial por parte de los freires en sus respectivos municipios, pero en un primer momento los términos sugieren donaciones mucho más simples, y en ningún caso se pudieron evitar las donaciones de particulares a la orden. En la práctica, estos subsidios se convirtieron en una importante fuente de ingresos. Por ello, cuando se comienza a cuestionar su pago desde mediados del siglo XIV, los santiaguistas lo reclamarán ${ }^{58}$.

Aun así, la orden seguía practicando el rescate de cautivos todavía en los primeros años del siglo XIV. En los estatutos reformados de 1312, se dice:

12. [...] E si algun pueblo fuere tan flaco que aya menester quitamiento de pecho por que pueble mejor, que lo fagan essos freires como mejor entendieren en Dios, e en sus animas, e ningund pariente de nos el Maestre, nin criado nuestro, nin judio nin moro, non sea cogedor, nin recabdador de los pechos, mas coganlos e recabdenlos pecheros abonados e raigados de cada logar.

21. Otrosi que ningund freire non sea ossado de aforrar cabtivo nin cabtiva sin licencia del Maestre o del Comendador Mayor. Qualquier que fuere a la redempcion que ende oviere que sea tornada en otros captivos a essa misma casa ${ }^{59}$.

partium in vinculis detentorum, nonnulli etiam tam nobiles quam alii dicti regis pia vestigia imitantes multa de bonis propriis eidem hospitalis modo simili donaverunt. Quare nobis humiliter supplicastis ut cum pro eo quod eliminatis iam de eisdem partibus per Dei gratiam sarracenis prefatos redditus et proventus in redemptionem huiusmodi convertere non potestis, heredes dictorum nobilium et aliorum donationes huiusmodi revocare presumant, providere super hoc paterna diligentia curaremus. Nos igitur vestris supplicationibus inclinati donationes tam per regem ipsum quam per alios predictos factas propter hoc hospitali prefato sicut sunt provide et in aliorum previdicium non redundant auctoritate apostolica confirmamus et presentis scripti patrocinio communimus. Ita quod in alios pios usus proventus et ressit huiusmodi convertatis. Nulli ergo omnino hominum liceat hanc paginam nostre confirmationis infringere, vel ei ausu temerario contraire. Si quis autem hoc attemptare presumpserit, indignationem omnipotentis Dei, et beatorum Petri et Pauli apostolorum eius se noverit incursurum. Data Lugdunum nonas septembris pontificatus nostri anno octavo». AHN, OM, Santiago, carp. 328, 12. BS, 180. Quintana Prieto, A., La documentación pontificia de Inocencio IV (1243-1254), Roma, 1987, II, docs. 655, 656 y 657, cit. Ayala, Las órdenes militares, 608, 660. Bonifacio VIII en 1299 confirmaría el libre destino de las rentas del hospital de Toledo: AHN, OM, Santiago, carp. $328,22, B S, 243-244$.

${ }_{58}$ Iradiel, "Bases económicas", 195-199; BS, 415; González, Fernando III, III, doc. 810. En 1312 hay disturbios en el hospital de Cuenca, al que atacan algunos ciudadanos, requisando las vestimentas eclesiásticas, camas, y otros objetos que allí hallaron. $B S, 258$.

59 BS, 262-263.

Al-Qanțara (AQ) XXVIII 2, julio-diciembre 2007, pp. 465-488 ISSN 0211-3589 
Aún más clara es la redacción de los establecimientos de la orden realizados por su maestre, el infante don Enrique en torno a $1440{ }^{60}$ :

Capítulo 27. A quién pertenecen los moros de las auenturas; y los que fueren de las casas, que no se puedan enagenar. No es duda, pues, que los comendadores y freyles no pueden enagenar los heredamientos que uvieren por razón y intuytu de las encomiendas y casas que de la orden tienen, que esso mismo enagenar no puedan los moros que uvieren por razón dellas. Por ende (siguiendo los establecimientos antiguos), ordenamos y establecemos que todos los moros y moras que los comendadores y freyles de nuestra orden uvieren de auenturas, o en otra manera qualquier, por razón de las encomiendas y casas que tuvieren de la dicha orden, que sean de la casa do fuere el auentura, y siruan en ella, y no los puedan los dichos comendadores ahorrar, ni hazer libres, ni vender, ni trocar, ni enagenar, saluo comprando luego otros tan buenos y de tal edad mejores, y que todavía queden para la tal casa o encomienda. Pero que los moros que los dichos comendadores o freyles compraren o heredaren o les dieren, o uvieren enviado talegas para los tomar, que los puedan vender o hazer dellos lo que les plazerá. Y el que lo contrario hiziere, que pague el moro o mora que assí vendiere, y quede a la dicha casa el dicho moro, y quede a nuestra prouidencia darle otra penitencia o pena, si bien visto nos fuere.

A partir de ese momento y hasta el término de la reconquista, las importantes encomiendas hospitalarias que se habían mantenido intactas después de la fuerte crisis de la primera mitad del siglo XIV, en la que, como Cuenca, algunos hospitales llegaron a ser enajenados, gozaban de una posición económicamente desahogada, fruto de la reconversión de sus actividades y de su adecuación a una economía de corte agrario y ganadero ${ }^{61}$. Los hospitales santiaguistas se convirtieron en encomiendas, y algunos de ellos siguieron utilizándose para el cuidado de enfermos. Sus restos arquitectónicos nos han llegado, pues, transformados por las modificaciones posteriores, o han sido destruidos por los avatares históricos, por lo que es prácticamente imposible hacerse una idea de su función inicial, a falta de excavaciones arqueológicas en los recintos. Los esclavos fueron desapareciendo paulatinamente de la documentación, y si suponemos que la tendencia a la liberación que se observa en los esclavos de otros colectivos se dio también en este caso, pasarían a formar parte de las comunidades mudéjares de sus lugares de origen, manteniendo su vínculo original con la orden. Pero todo eso escapa al período cronológico que tratamos en este trabajo.

${ }^{60}$ Regla, 340.

${ }^{61}$ Iradiel, "Bases económicas", 186; Sainz de la Maza, La Orden de Santiago, I, doc. 192; Ayala, Las órdenes militares, 608.

Al-Qanțara (AQ) XXVIII 2, julio-diciembre 2007, pp. 465-488 ISSN 0211-3589 


\section{DOCUMENTOS}

\section{7, abril, 5.}

Venta de un esclavo moro por D. Gonzalo Martínez, comendador del hospital de pobres y leprosos de Villa-martín, de la Orden de Uclés, a D. Abdallá, moro de Sahagún.

AHN, OM, carp. 325, 23.

In Dei nomine. Connocida cosa sea a los omes qui agora son e seran adelante. Cuemo yo don Gonzaluo Marquez fraire de la orden de Ucles, e comendador de la casa de Ville Martin, vendo a vos don Abdalia el mo[ro d]e Sant Fagund fiio de don Merlin, un moro que avemos que ha nombre Hameth, por L maravedis alfonsis, onde so bien pagado de precio e de [a...c] e no remanez ninguna cosa por dar. E otorgo vos que de oy dia en adelante, que fagades del a vuestra guisa de vender o de enpenhar o de fazerle horro, tan bien en vida cuemo en muerte. E si alguno de nuestros o de estranhos este fecho que yo fago quisies demudar o quebrantar, sea maldito e aya la ira de Dios omnipotente plenera inient, e peche en coto al rey cien maravedis hi el danno que hi vinies dupplado, e diessen a vos vuestro moro dupplado, hi el precio que vos distes a nos que lo dupplen a vos o a qui lo vuestro heredar sin ningun entredicho. Fecha es la carta dia domingo, $\mathrm{V}$ dias andados del mes de abril sub era millesima ducentesima septuagesima quinta. Regnando el rey don Fernando con su madre la reyna dona Berenguiella en Castiella, en Toledo, en Leon hi en Gallizia hi en Cordova. Obispo en Palentia don Te1lo, [al]frerez del rey, vagant; mayordomo del rey, don Garci Fernandez; sennores en Carrion don Rodrigo Gar-[roto]-drigo Rodriguez; merino mayor del rey, don Moriel; so su mano merino en tierra de Carrion, Domingo Y-[roto] de la villa de Carrion don Amel de la Boxera, Pedrivanhes fiio de dona Aritunha, Pedro Garcindoth, Juan Ferrandez fiio de don Bernardo, don Thomas, don Guigelmo el portero, Juan Guilhem pelliço, don Juan hermano de Pedro vinadero, Beneyto fijo de Domingo Loreintez, don Omar, don Jucef, don Espinel, don Franco, fiador de sanamiento, de furto e de jubina cuemo el rey manda, don Ferrando el linacero qui mora en Carrion en barrio de mercado. E por que esta carta sea firme hi estable, yo don Goncaluo Martinez fraire nombrado de la orden de Ucles e comendador de Ville Martin cerca Carrion mandela poner mio suyello. Johannes gerator sacerdos scripsit et confirmat et hoc signum [signo] fecit.

1234, diciembre. Moya.

Carta de acuerdo entre el concejo de Moya y el comendador de la casa de la Merced de Moya, don Gonzalo Díaz, por la que se negocia la forma en la 
que percibirá los 1.200 maravedies del valor de seis esclavos musulmanes que se habian escapado de Moya y habían sido capturados por los caballeros y peones de Requena.

AHN, OM, carp. 100-2, 18.

Ed. Iradiel, p. 228-229, doc. 19.

Hec est carta et memoria del abenencia que fizo el conceio de Moya con don Gonçaluo Diaz comendador de la casa de la Merced de Moya sobre seis moros que perdieron de la casa de la Merced de Moya ques escaparon de las prisiones e estos moros auien taiado por mill e doscientos morabetinos. Et fue tras estos moros don Gonçaluo del Alcoton e alcanzolos e prisolos e aduzielos a Moya. Et nos el conceio auiemos pazes con los de Requena e ixieron cavalleros y peones de Requena e tolieron los moros a don Gonçaluo del Alcoton e levaronlos a Requena, e aquelos moros eran de la tierra con que auemos nos guerra e los de Requena. Et sobre estos nos el conceio mandamos pendrar a don Gonçalvo Diaz de Requena por estos moros sobredichos. Et el pendro moros e bestias de Requena, e por ruego de conceio dio esta prenda don Gonçaluo Diaz por docientos morabetinos. Et sobre esto mando el conceio a don Gonçaluo Diaz e al comendador que touiese la casa de la Mercet de Moya, que a las primeras pazes que ouiesemos nos e los de Requena que pendrase de Requena dont meior pudiesse, por los mill marauedis que fincaua en clamo. Et est anno regnaua en Castiella, en Tolledo, en Leon et en Gallicia don Ferrando. Sennor de Moya don Tello Alfonso, alcayat de Moya Don Diego de Don Aparicio, iudez don Pedro de Xemena, alcaldes don Buenhache et don Gil del Inlar et Climent de Marha et don Perez el Pozuello et Blasco de Felmiro. Escriuano don Iohan carnicero de obra, merino don Fortuno de Rida, sayón Pero de la Gordiella, andadores Gonçaluo Perez et don Polo et don Blasco. Esta carta fue fecha en el mes de deziembre quando era el era de 1272 annos. Et desta carta fueron testigos oydores et uehedores don Ferran Lopez de Varea alcayat de Terol, et don Miguel Diaz alcayat de Castiel et don Furtado alcayat de Ademuz et don Gonçaluo Diaz comendador de la casa del ospital de Castiel. Et todos los jurados de Moya por nombre don Gonçaluo et don Roy Gomez, et don Gonçalo del Alcoton et don Roy Sanchez et don Pero Xemenez de Calada et don Galindo de Palacio et presente todo el conceio. Santiago Lopez me escripsit. Hoc signum fecit. [conserva el cordón del sello pendiente].

Recibido: $24 / 01 / 07$

Aceptado: 07/06/07 